\title{
Pandemia e educação na escola pública: um relato possível e incompleto
}

Lara Tatiane Matos ${ }^{1}$

Submetido em: 09/09/2020

Aprovado em: 27/10/2020

DOI: $10.5965 / 23580925242020093$

1 Doutora em Teatro pela Universidade do Estado de Santa Catarina (UDESC). Professora/atriz e produtora de teatro. E-mail: laratmatos@gmail.com 


\section{RESUMO}

Durante a primeira pandemia do século XXI, em meio a uma crise política e sanitária e dentro do primeiro confronto propriamente dito entre presença e realidade virtual, dei meus primeiros passos como educadora interessada em educar. Como professora não via espaço para inventar novos modos para além das imposições estruturais da escola pública. Na pandemia a estrutura se rompeu e, defrontada com a falta de respostas prontas, a escola precisou se abrir para novas ideias. O desconforto do momento permitiu a expansão das possibilidades e assim, pela primeira vez, me vi gozando de certa liberdade para experimentar. Neste trabalho pretendo expor uma realidade imprevista e tentar entender com 0 leitor o que aconteceu, do ponto de vista educacional como professora de artes/teatro numa pequena escola da rede municipal de Florianópolis.

Palavras-chave: educação, pandemia, teatro.

\section{ABSTRACT}

My first steps as educator were taken while the world was experiencing the first pandemic of the 21st century and inserted in the realm of a nacional political and health crisis. Right on the spot, we were obliged to shift from face-to-face to virtual reality. While teaching at a Public School, I had no room to think or create new ways beyond the rigid and old established guidelines. But with the strike of the pandemic, these guidelines became useless and our school was begging for new ideas. This disease allowed me, for the first time, to enjoy some freedom to experiment. In this work, I will expose this unpredicted reality, from the point of view of an Art and Theater teacher, and try to underline its consequences to a small public school in Florianópolis.

Keywords: pandemic, education, theater. 
Do ponto de vista daquele que acaba de chegar e não encontra mais adultos que possam dar uma direção. Nós, os adultos, estamos diante de impasses para os quais a tradição não tem resposta. Escutar os jovens e suas invenções é uma posição política.

(Ana Lucia Holck)

No final de março do ano 2020 as aulas das escolas públicas municipais de Florianópolis foram suspensas ${ }^{2}$, inicialmente por dezessete dias, como medida de controle da contaminação pelo SARS-CoV2, causador da doença COVID-19. Era pouco esperado que aquilo que ficou chamado "quarentena" ou "confinamento" durasse mais do que um mês, ou no máximo dois, ou seja, a expectativa era que as aulas suspensas não se estendessem. A primeira atitude da Secretaria de Educação foi suspender as au$\operatorname{las}^{3}$, ou adiantar as férias do recesso de julho, para não interferir na contagem de dias letivos e horas aulas exigidas pelos órgãos superiores. No entanto, à medida que o tempo passava, ficava claro que as previsões não eram animadoras, pelo contrário, os níveis de contaminação eram baixos, estávamos na subida da montanha russa.

A partir daquele momento as escolas e Secretaria Municipal de Educação ${ }^{4}$ começaram a se organizar para encontrar maneiras de não só garantir alguma aprendizagem como aliviar a pressão sobre os cuidadores, que se encontravam diariamente sozinhos com crianças sobrecarregadas com a falta de liberdade para ir e vir, e com uma crescente ansiedade. Inicialmente a Secretaria de Educação contratou serviço da empresa americana de tecnologia Google, o Google G Suits ${ }^{5}$, um pacote fechado com armazenamento e diferentes aplicativos vinculados a uma conta institucional do e-mail do Google, o Gmail. Em um dos apli-

2 Florianópolis. Decreto N² 21.352, de 17 de março de 2020

3 Florianópolis. Decreto N²1.368, de março de 2020.

4 Florianópolis. Lei $N^{0} 10.701$, de 22 de abril de 2020.

5 Link para site de apresentação do programa: https://workspace.google.com. br/intl/pt-BR/ 
cativos desta plataforma, o Google Sala de aula, a escola poderia ser organizada em turmas, e ali os professores compartilhariam atividades em diferentes formatos e os estudantes através de um e-mail institucional poderiam acessar esses materiais. 0 aplicativo, bastante intuitivo, é um dispositivo de fácil acesso, o que se torna essencial em comunidades com diferentes níveis de conhecimento sobre tecnologias. Assim, inicialmente a escola abriu as "salas de aula virtuais na plataforma Google" apenas para a ambientação dos professores, os alunos iniciaram suas "atividades remotas" através de dois desafios, cada um de uma semana, veiculados na rede social Facebook. Nessas duas semanas os professores puderam testar as salas e começar a produção de materiais virtuais e também formular materiais para serem impressos.

No início do ano, antes da pandemia se instaurar e levar ao confinamento, me propus vencer uma batalha na sala de aula que há tempos eu percebia ser perdida: aquela contra o uso do celular. Sempre pareceu muito pouco produtivo e bastante estressante o jogo da inspeção constante sobre quem está acessando o celular na sala de aula. Essa me parecia uma batalha perdida também porque não parecia ser do interesse dos pais que isso fosse regulado ${ }^{6}$.

Minha batalha semi perdida com o celular fez traçar uma estratégia: me juntar ao inimigo. Decidi que ia usar a presença do dispositivo para compartilhar materiais com mais visualidade, principalmente no que diz respeito aos conteúdos que envolviam história do teatro ou a exemplificação de atividades práticas com espetáculos e cenas encontradas facilmente na internet. Minha dúvida neste ponto consistia em como garantir

6 Se por um lado me parecia bastante justo que os pais oferecessem celulares para ter controle sobre o paradeiro dos filhos (e para o acesso dos filhos aos pais em casos de urgência), parecia que a educação sobre os momentos corretos de acessar o dispositivos precisava de uma imposição com mais firmeza a partir das famílias, e isso, não existia. Também não fazia sentido ignorar o fato de estarmos todos cada vez mais conectados, parecia hipocrisia cobrar dos pré-adolescentes e adolescentes que se desconectassem por quatro horas se nem mesmo os adultos conseguem fazer isto. A questão da "hiperconectividade" é um problema que pode estar afetando todos nós, de todas as faixas etárias. 
que os alunos se concentrassem nos temas que eu propunha, e como garantir que eles não se distraíssem em outros sites ou aplicativos. Para isso, idealizei um blog para cada duas turmas de faixas etárias mais próximas, este blog concentraria os materiais e as referências centrais dos conteúdos, seria um link fácil para compartilhar com os alunos nos grupos de Whatsapp, e certamente deveria ter um tom leve, trazendo imagens, gifs, vídeos e textos escritos em uma linguagem acessível.

A escola fazia reuniões gerais duas vezes por semana, tentando resolver problemas centrados na acessibilidade dos estudantes, era preciso considerar que em se tratando de uma escola pública, muitas famílias não tinham computadores, e quando tinham celulares os pacotes de dados de internet eram restritos, fazendo com que a conectividade para realização de tarefas escolares fosse precária. A equipe pedagógica da escola trabalhou incansavelmente na busca de alternativas, e então chegamos a um ponto de concordância sobre os materiais/meios que poderíamos buscar para acessar estes estudantes e oferecer as atividades remotas.

Foi decidido que as atividades dos anos finais dos sextos aos oitavos anos, seriam postadas na sala de aula virtual, em diferentes formatos (arquivos, vídeos, apresentações) estas mesmas atividades seriam transformadas para o formato de documento (Microsoft Word) para ser impresso e entregue às famílias sem acesso à internet, neste caso os pais ou responsáveis se deslocariam até a escola para buscar essas atividades impressas disponibilizadas.

Para os anos iniciais, do primeiro até o quinto ano, as atividades seriam postadas na sala de aula virtual e também enviada para o grupo de Whatsapp da turma, onde constavam os números de telefone de contato das famílias. O objetivo era impedir ao máximo a necessidade de deslocamento dos cuidadores, por isso não foram propostas atividades impressas.

No caso das atividades dos anos finais e dos anos iniciais, o aplicativo Google Formulários se mostrava o mais completo, pois além de ser projetado para colher dados colhidos a partir de respostas individuais, tinha espaço para arranjar diferentes for- 
matos de questões, desde objetivas a dissertativas. Ali mesmo também era possível inserir links, vídeos e imagens, e o mesmo formulário possuía a opção de disponibilizar um botão para upload de imagens e vídeos como resposta a uma questão. Além disso havia o link gerado para acessar o formulário, curto e prático, capaz de abrir com facilidade em qualquer navegador tornando o formulário e a atividade extremamente acessível, mesmo para quem tem à disposição um pacote de dados de internet limitado. Para os anos finais este mesmo material deveria então ser remodelado para caber no formato documento, dentro do formulário estipulado pela escola para ser impresso.

Depois de um início desesperador através da constatação de que seria um desafio trabalhar dentro destas condições em uma disciplina prática de uma arte que exige a presença física para se estabelecer. Como entender a cena teatral se o que media o entendimento neste caso é a tela? A resposta desta questão precisava ser extrapolada, não podíamos nos dar ao luxo de querer ensinar, apegados aos pressupostos do teatro, e passar por cima da realidade dos nossos estudantes. A pergunta sobre como manter os princípios do teatro na educação remota precisava dar espaço para outras questões mais importantes. Era importante perceber o momento em que a atividade precisava deixar de ser única e exclusivamente um mecanismo de aquisição de conhecimento para se tornar um respiro, uma saída na rua sem sair de casa, um encontro com os colegas sem encontrar fisicamente, uma conversa com alguém de fora para distanciar do relacionamento muitas vezes carregado com os pais e familiares.

Era preciso acima de tudo respeitar as fases, se com os pequenos era preciso criar mecanismo que colocassem família e crianças se divertindo na hora das atividades, com os adolescentes era preciso estabelecer o espaço de individualização, um lugar para ir e se encontrar para longe das relações parentais, respirar para além da família. Para ganhar confiança com os anos finais, me propus começar contando histórias, histórias divertidas a partir da história do teatro. As publicações precisavam ser leves, sempre partindo de perguntas que naturalizavam 
o estranhamento que eles deviam sentir ao ouvir falar de Commedia dell'Arte ou Teatro Nô. Estas histórias eram intercaladas com perguntas sobre o conhecimento que eles tinham ou não sobre o tema, somados a questionamentos que exploravam o absurdo das situações relatadas.

$\mathrm{Na}$ atividade focada em teatro de bonecos por exemplo, decidi criar um formulário com texto introdutório, questões, gifs e vídeos sobre a Cia. francesa Royal Deluxe ${ }^{7}$ e seus encantadores bonecos gigantes. Além de brincar questionando se eles sentiriam medo de ver um boneco gigante abrindo os olhos em direção a eles, também perguntava se havia outra manifestação cultural brasileira, onde se viam bonecos e tecnologias parecidas com os utilizados pelo grupo criador da Pequena Gigante. Muitos deles relacionavam o carnaval e seus bonecos com a estrutura usada pela Cia. Royal Deluxe.

\footnotetext{
Agora que você já viu o tamanho real da boneca, perceba os detalhes do rosto dela e do cachorro. $O$ que você acha? Aposto que ia ficar com medo se ela abrisse o olhão perto de você... :0
}

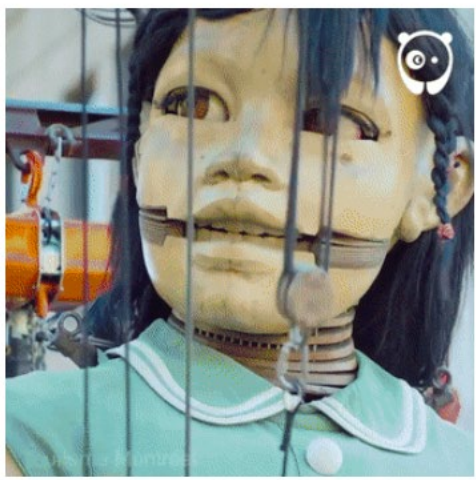

Figura 01: Parte do formulário sobre teatro de bonecos para os anos finais

Fonte: arquivo da autora

Era preciso perceber que alguns temas podiam ser trabaIhados com diferentes fases, o teatro de bonecos por exemplo atraía estudantes desde o sexto até o nono ano. Já o trabalho

7 Link para o site da Cia.: http://www.royal-de-luxe.com/en/company/ 
com os textos de Brecht e sua contextualização para pensar o horror do nazismo era cabível em um trabalho com os oitavos e nono ano, mas não pareciam interessantes para os sexto e sétimo anos.

Com os anos iniciais era preciso ter em mente os familiares, as crianças nesta fase possivelmente demandavam ajuda dos responsáveis para acessar as atividades e por isso era fundamental que a atividade fosse de um tamanho médio, não muito longa, muito interativa, com bastante visualidade, e que envolvesse o imaginário adulto no sentido de trazer elementos também da infância deste adulto. Durante um mês específico trabaIhei com a peça Os saltimbancos, a partir das ótimas gravações da peça homônima gravada e disponibilizada no Youtube pela Odeon Cia. Teatral ${ }^{8}$.

No formulário aprendemos a letra das canções com gifs e imagens divertidas como ilustração. Também haviam pequenos questionários sobre o tema da peça ou uma relação entre um tema discutido na peça e a realidade de cada crianças. Por exemplo, se cada animal de Os saltimbancos tinha uma cidade ideal, qual era a cidade ideal daquela criança que fazia a atividade? Quais eram as partes favoritas da cidade onde ela vivia? Quem ela via no caminho da escola? As questões se desdobravam a partir do tema principal. O final da atividade consistia em assistir um trecho da peça teatral, e como tarefa deviam escolher entre selecionar um dos personagens da peça, se caracterizar e fazer uma fotografia para enviar pra professora, ou desenhar um dos personagens e fotografar para enviar pelo formulário, ou ainda gravar um áudio imitando um dos animais da peça variando suas emoções (bravo, feliz, cansado, etc.). As atividades não poderiam ser obrigatórias e precisavam ser variadas para oferecer possibilidades para famílias e estudantes.

Para além do formato das atividades e da distância, outra mudança se deu no campo da escola que merece ser considerado, a proximidade entre os profissionais da escola. As reuniões que antes se concentravam apenas nos conselhos de classe, a

8 Disponível em: https://www.youtube.com/watch?v=WSuwCY7YPf0 . Acesso em: $12 / 11 / 2010$ 
cada três meses, agora se davam duas vezes por semana, permitindo aos profissionais da escola mais que qualquer coisa, ouvir uns aos outros. As dificuldades que muitos apresentavam e a disposição dos demais em ajudar a superar estas dificuldades também foi surpreendente e bonito. Além destes estreitamentos das relações, as atividades foram aproximando professores de diferentes disciplinas, como exemplo, a união dos oitavos e nonos anos em uma live (ou encontro virtual, teleconferência) para discutir o filme $O$ menino do pijama listrado, com foco principalmente na história do nazismo na Alemanha que o filme traz.

Para esta atividade juntamos os professores de Língua Portuguesa e História e Teatro, e trabalhamos cada um em sua disciplina as duas semanas anteriores à live sobre temas referentes ao período histórico do nazismo. No teatro, para fazer um link com o tema usei a obra de Charles Chaplin, principalmente o Grande Ditador' ${ }^{9}$ e para aprofundar o tema trouxe a obra de Berthold Brecht, principalmente a peça Aquele que diz sim, aquele que diz não. Em diferentes atividades usei as duas abordagens sobre o nazismo, em Brecht e Chaplin, cada um em sua obra, e além disso trouxe as confluências de suas histórias, suas influências e suas trajetórias no cinema e no teatro.

A atividade foi um sucesso pois preparamos os estudantes e eles se sentiam seguros para comentar, fazer analogias e perguntas, e muitos outros professores participaram, tornando o evento abrangente e não necessariamente focado em festas ou premiações, mas uma atividade educativa e mais do que isso, um debate.

A fase seguinte se deu com a necessidade de troca, na sala de aula a troca é uma constante, alunos comentam as atividades uns dos outros, sugerem, trabalham juntos e melhoram suas atividades a partir do entendimento junto com o outro. Dentro disso era necessário criar um lugar onde o estudante visse seu trabalho e do colega, para isso desenvolvi dois sites, um o Mural da quarentena dedicado ao trabalho dos anos iniciais, e o Mural das artes, onde eram postados os materiais dos ano finais, atu-

9 Disponível em: https://www.youtube.com/watch?v=pHZ46sQkzqU. Acesso em: $12 / 11 / 2020$ 
alizados semanalmente, os links dos murais atualizados eram sempre enviados como tarefa inicial de uma nova atividade.

Como diz o título deste texto, se trata de um relato possível e incompleto tanto no que diz respeito a ângulos de visão, pois só poderei saber do resultado alcançado quando estiver de frente com meus estudantes e em contato com suas famílias, quando ao que diz respeito a inconclusão deste processo de confinamento. Seguimos separados pelas telas, seguimos buscando maneiras de chegar aos estudantes que ainda não chegamos, de criar novos materiais que mantenham o interesse daqueles que já estão conosco. Um trabalho exaustivo que exige muito desdobramento, mas como dito no início, que permite a invenção. Certamente não sairemos ilesos deste processo, a tecnologia sempre tida como espaço apenas de entretenimento terá certamente um novo ângulo depois desta pandemia, esperemos que seja para um uso mais responsável e maduro, inspirado pelos momentos didáticos das aulas.

\section{REFERÊNCIAS}

HOLCK, Ana Lucia L. Entrevista: adolescência e escrita. [Entrevista concedida a] Isabel R. B. Duarte In: Acervo da Escola Brasileira de Psicanálise. Disponível em: https://www.ebp.org. br/entrevista-adolescencia-e-escrita/ acesso: 31/08/2020

FLORIANÓPOLIS. Decreto $N^{\circ}$ 21.352, de 17 de março de 2020. Declara situação anormal, caracterizada como situação de emergência no município de Florianópolis, em razão da pandemia decorrente da infecção humana pelo novo Coronavírus (COVID-19), o avanço das infecções no Brasil e dá outras providências. Disponível em: shorturl.at/cltDS acesso 09/11/2020

FLORIANÓPOLIS. Lei No 10.701, de 22 de abril de 2020. Autoriza o regime especial de atividades de aprendizagens não presenciais para a educação básica da Rede Municipal de Ensino de Florianópolis, para fins de validação da carga horária mínima 
anual exigida para o cumprimento do ano letivo de 2020, em consonância com a prevenção da pandemia do coronavírus (covid-19) e dá outras providências. Disponível em: shorturl.at/ ilEKT acesso 09/11/2020

FLORIANÓPOLIS. Portaria 220 de 24 de julho de 2020. Institui recesso escolar no âmbito da Rede Municipal de Ensino de Florianópolis, em caráter excepcional, em razão da Pandemia do novo Coronavírus (COVID 19). Disponível em: shorturl.at/hjEGO acesso 09/11/2020

FLORIANÓPOLIS. Decreto N²1.368, de 27 de março de 2020. Prorroga as medidas de enfrentamento ao COVID -19 e dá outras providências. Disponível em: shorturl.at/svLR7 acesso 09/11/2020

CHAPLIN, Charles. | O Grande Ditador (The Great Dictator) 1940 - Legendado - Vídeo. 2h. Canal Domínio Público 2017 Disponível em: https://www.youtube.com/ watch?v=pHZ46sQkzqU acesso em 12/11/2020

CIA. ROYAL DELUXE. disponível em: http://www.royal-de-luxe. com/en/company/ acesso 11/12/2020

ODEON CIA.TEATRAL. Espetáculo "Os Saltimbancos" - Canal Instituto Odeon. 2015 - vídeo -1h. disponível em: https://www. youtube.com/watch?v=WSuwCY7YPfO acesso em 11/11/2020 